\title{
Advances and challenges in the evolving field of international entrepreneurship: The case of migrant and diaspora entrepreneurs
}

\author{
Hamid Etemad ${ }^{1}$
}

Published online: 7 June 2018

C) Springer Science+Business Media, LLC, part of Springer Nature 2018

\section{Introduction}

The Journal of International Entrepreneurship (JIEN) is pleased to present this special issue, formally entitled as the "Migrant and Diaspora Entrepreneurs in International Entrepreneurship". This title was articulated more than two years ago. The corresponding call for papers $(\mathrm{CfP})$ called for papers elaborating and expanding on the integral constituents of the CfP's topic. As a result, this thematic special issue carries the same title. However, and similar to the expanding and evolving field of international entrepreneurship (IE), authors and co-authors of papers appearing in the issue, as well as the guest editors, have raised concerns regarding certain aspects of the field, including the existing boundaries and scope of IE. Collectively, they expanded the topical coverage beyond the strict topics of the CfP's formal title. Although this special issue (SI) addresses theoretical and practical issues related directly, or indirectly, to Migrants and Diaspora Entrepreneurship topics within and at the margins of IE, it could have alternatively called for papers addressing "Advances and Challenges in the Evolving Field of International Entrepreneurship." Therefore, this introductory note will first explore selective events that set the stage for this thematic special issue. It will point to the perceived difficulties and challenges to the field before highlighting selective features of the issue.

Structurally, this introductory note will unfold as follows. First, it will explore briefly the evolving phenomenon of increased worldwide migration and on-the-move populations, resulting in increased migrant and diaspora entrepreneurs with potential relationships with, if not impact on, IE, and possibly drawing attention to the emergence of new frontiers in the field of international entrepreneurship as a whole. Second, it will recognize the efforts of the guest editing team of seven scholars and portray briefly the

Hamid Etemad

hamid.etemad@mcgill.ca

$1 \quad$ McGill University, Montreal, Canada 
process that produced seven related papers appearing in this thematic SI. Third, it will highlight a few examples of the theoretical issues, if not challenges, that the general topic of migrant and diaspora entrepreneurship has brought to the fore, some of which the guest editing team had to address, and others have remained unresolved that are in need of further scholarly attention. This note will underscore a few of such issues in order to call for collective efforts in resolving them, before a brief conclusion and discussion at the end.

\section{Emerging entrepreneurship in diaspora, migrants, and people on the move}

The general patterns of increased migration and mobility was highlighted by a 2017 United Nations' Internal Migration Report that suggests "There are 258 million people living in a country other than their country of birth - an increase of $49 \%$ since 2000 " (United Nations 2017). The same report also suggests that some " $3.4 \%$ of world's inhabitants today are migrants" and "the number of migrants as a fraction of population residing in high-income countries rose from $9.6 \%$ in 2000 to $14 \%$ in 2017 " (United Nations 2017). ${ }^{1}$ The recent massive movements - e.g., the ongoing wave of asylum seekers, migrants, and refugees arriving on the shores of European countries - are in part due to increased strife in the troubled parts of the world forcing people to seek opportunities elsewhere. ${ }^{2}$ It is also in part due to the removal of barriers and openness of some countries to opportunity-seeking immigrants for their innate, acquired, and necessity entrepreneurship, resulting in start-up enterprise that generate employment, income, and wealth on ongoing basis. The latter is a relatively recent phenomenon, while the former has been episodic and countries have responded accordingly. For example, Canada accepted a large number of asylum seekers, migrants, and refugees from Vietnam in the aftermath of the Vietnam War, who have all become highly contributing citizens already. ${ }^{3}$ Similarly, the more recent wave of migrants from Syria is another example. In contrast to those large episodic waves, Canada accepts potential entrepreneurs as regular immigrants with the prior expectation that they will become contributing citizens soon. This immigration policy has proven to be successful. It is a common knowledge that immigrant entrepreneurs have created more successful innovative businesses than aspiring entrepreneurs born in Canada have. Consequently, the emerging nascent entrepreneurship, partly rooted in international entrepreneurs, has become multi-cultural and increasingly with international orientation(s) than ever before. Some of these "international entrepreneurs"-people who have crossed boarders - set-up start-up enterprises and internationalize their firm's activities - e.g., outsourcing from their countries of origin for sale in Canada and the USA, as well as producing partially, or fully, in Canada for selling to the rest of the world, including their respective countries of origin, over time.

\footnotetext{
${ }^{1}$ For more details, please see the United Nations, Department of Economic and Social Affairs, The International Migration Report 2017, available at https:/www.un.org/development/desa/publications/

${ }^{2}$ In the balance of this introductory note, the term "migrants" will be used to refer to the group of people on the move, regardless of their actual status as asylum seeker, refugees, migrants, etc.

${ }^{3}$ Canada accepted more than 110,000 of the so-called Boat People as migrants from Vietnam between 1975 and 1985. These migrants have become successful Canadians and their sons and daughters have fully integrated into the Canadian cultural mosaic.
} 
Consider for example, that in the city of Montreal, where McGill University is located and I work, more than a half of the population trace their roots back to migration, some relatively recent and some going back a few generations. More than 20 large "ethnicities" have established formal business and community organizations that are manifestations of their vibrant presence and active contributions. They are also active participants in the civic, cultural, and political life of the city, province, and Canada as a whole. More importantly, however, they have engaged in entrepreneurial and business activities in the city and beyond. They actively promote ethnic entrepreneurship and ethnic businesses in all facets of business life. The early immigrants may have started as necessity entrepreneurs at first; but their establishments have grown into successful family businesses over time, with much better educated and capable entrepreneurial second and successive generations at the helms now. In some cases, the early family businesses have transformed into publicly held corporations that would conduct international business worldwide. There are many successful examples and this note will refer to only a couple in favor of time and space.

Aldo Corporation, founded by Aldo Bensadoun in 1972, designs, produces and sells shoes and wardrobe accessories, among others, worldwide. Aldo's net revenues exceeded \$2.2 Billion in 2015. Bombardier Aero Space (with revenues of $\$ 16.28$ Billion USD in 2016), the third largest civilian airplane maker in the world (After Air Bus Industries and Boing), is another example of a typical family firm becoming a prominent international business operator with diverse product lines. Earlier on, Bombardier invented the early version of snowmobile for local transportation in the harsh Canadian winter conditions at first and it has become one of leading airplane, train and mass transportation manufacturer in the world now. ${ }^{4}$

In fact, the early migrants who decided to settle in Montreal, built productive industries and communities, on which Montreal has thrived over the past three and-a-half centuries. ${ }^{5}$ Aside from their economic contributions, these ethnic groupings add an unmatched richness to the cultural vibrancy of the city. Montreal is not an exception, as practically most other Canadian cities exhibit similar trends. In most cases, the organized community of the old, and the more recent immigrants, welcome and sponsor new migrants to the city and to Canada. They also support their migrant and diaspora entrepreneurs in most cases. As a direct result of migrant entrepreneurship, employment, income, and wealth are created and international trade and investment continues on a regular basis. It is difficult to imagine that these processes are unique to Canada and to Montreal.

The above illustrations are typical manifestations of strong linkages between and among migration, entrepreneurship, and international entrepreneurship. Aside from their obvious fitting into fields, and sub-fields, such as sociology, migration, ethnic entrepreneurship, economic geography, and migrant or diaspora entrepreneurship, the theoretical question of whether or not the topic of migrant and diaspora entrepreneurship belongs to international entrepreneurship has not been considered extensively. This thematic special issue covers the topic and suggests that connections and linkages are undeniable and relatively strong. My comments, below, raise related issues and add further elaborations that point to a few related challenges and questions.

\footnotetext{
${ }^{4}$ Skidoo, a reliable snowmobile, made by Bombardier, is still the main mode of transportation in the polar regions of Canada.

${ }^{5}$ Montreal celebrated its 350th anniversary of its establishment by its original French settlers in 2017.
} 


\section{The guest editing team and editorial processes}

A team of seven prominent scholars accepted the onerous task of guest editing and managing this thematic special Issue. The planning for this issue started two years ago. Dr. Maria Elo served as the initial contact point between the team and the Journal of International Entrepreneurship (JIEN). The co-guest editing team's research and writing spans over a very wide, different, but complementary, disciplines, ranging from economics and entrepreneurship to philosophy, politics, and sociology that easily subsume the dynamics of entrepreneurship, international business, diaspora, and migration. Collectively, the team turned out to be inquisitive, if not critical, of arguments of each, and every, paper on topics related to those articulated in the CfP, as they examined all presented arguments from their own rich multidisciplinary perspectives. This multidisciplinary team invested a lot of effort in receiving articles, reviewing them, and communicating with reviewers, authors, and with one another for reaching a final consensus decision regarding a paper.

The process of reviewing and revision started more than a year-and-a-half ago and practically all papers in this issue have been subjected to the Journal's routine process of two reviews, and even more in some cases, with corresponding revisions, before being accepted. To facilitate the review and revision processes, capabilities of the JIEN editorial office (JEO) and those of the Production Department of the journal's publisher, Springer Nature, assisted the guest editing team's efforts in managing the SI. On behalf of the journal, I am grateful for all these efforts.

It is noteworthy that the journal has an open reviewing policy, where the author(s), reviewers, JEO, and the publisher's officials have access to all relevant documents and information; and this SI was no exception. The papers of this issue, in your hands, have gone through, and thus benefited from, the routine rigorous reviewing processes of the journal. However, the list of theoretical difficulties and challenges, some of which will be highlighted later here, were raised directly, or clearly implied, by papers submitted for consideration in this special issue. I will enumerate a few of the fundamental and structural issues in the next section in order to invite a collective discussion of them over time.

\section{Selected highlight of IE's fundamental difficulties and corresponding challenges}

As briefly stated earlier, the young field of IE has expanded and evolved over the past three decades. This expansion and evolution has not been organized and systematic, but organic and issue-driven. In the process of research, scholars facing difficulties and challenges raised questions, some practically and some theoretically oriented, which in turn gave rise to theoretical discussion and scholarly debate in scholarly gatherings and publications that consequently advanced the state of the art in young field of IE. While the evolving theory and advancing research have already resolved some of such challenging issues, others have remained, which necessitate further scholarly, theoretically, and even practically oriented debate to either resolve them fully, or to point to promising pathways for their resolutions eventually. This is not particular to a young field, such as IE, as it occurs routinely in other fields, especially in Sciences. If and 
when an issue (or a phenomenon), previously assumed or expected to belong to a field (or fit clearly into a field), violates some principal aspect(s) of the established field, then both the issue and the violation need a careful re-examination for further clarification and improvements.

I suggest that the phenomenon of migrant and diaspora entrepreneurship poses a potential challenge to IE as a young emerging field and deserves a collective scholarly examination. ${ }^{6}$ Furthermore, the nature and the extent of challenges need further and careful examination. As examples, let us consider two broad categories of challenges to set the stage for our further collective discussions:

1. When an isolated aspect of the field is questioned. This is when the question involves an isolated aspect-e.g., the traditional unit of analysis, an implied assumption, a boundary condition, and scope of coverage, without implication for other aspects.

2. Alternatively, when the challenge is much broader than one isolated aspect. This is when certain integral principles are implicated with implication for other related definitions, factors, variable, etc.

On the difficult side, such challenges pose a feeling of unease and uncertainty in the field's affected circles. On the bright side, however, as such challenges come forth, regardless of the extent of difficulty, efforts directed to debating and resolving them result in progress forward and become more entrenched and the field evolves further consequently. In the balance of this elaboration, a list of few issues posing, or implying, challenges will be briefly discussed. The challenge before us is their further theoretical exploration and empirical verification.

\section{The early definitions of international entrepreneurship and its evolution to entre-} preneurial internationalization International entrepreneurship (IE) was initially conceived at the intersection (or cross section) of the two fields of international business and entrepreneurship, while both were going through their own evolution. International business pertained to larger companies, such as multinational enterprises (MNEs), expanding the reach and scope of their international business in stages from home to similar, possibly neighboring, markets to those farther apart over time. Johanson and Vahlne (1977 and 1990) were among the early prominent scholars advancing such forward-moving views. In contrast, the younger and expanding field of entrepreneurship pertained to domestically oriented smaller enterprises without much concerns for international business and foreign markets. The path-breaking work of Loustarinen (1994, 1988, and 1980) followed by Welch and Loustarinen (1993) suggested that, the smaller firm's outsourcing from, and collaborating with, competitive international sources could increase the smaller firm's (or even a larger firm's) competitiveness at home and possibly in international markets as well. This was both an opening window through which entrepreneurial firms could collaborate with other international firms, regardless of their respective sizes, and also "internationalize" their supply chain and value nets respectively; but such internationalization was called as

\footnotetext{
${ }^{6}$ Another potential issue to consider is tourism that "internationalizes" the location-bound assets, capabilities, goods, and services. We will briefly explore this problem later on.
} 
"backward or inward," in contrast to "forward and outward" internationalization. In fact, the progressive removal of barriers to investment, trade, and factor-input motilities, stimulating globalization, facilitated supply chains and value net optimization across borders, countries and regions of the world (Friedman 2005), regardless of the firms' size and initial orientation. Etemad (2005 and 2004) suggested that these evolutionary trends would point to a need for reconceiving IE so that entrepreneurs could actively decide on the direction(s), form, process, and extent of internationalization. JIEN adopted the suggestion and referred to the evolutionary change of emphasis as entrepreneurial internationalization (or EI), where not only entrepreneurial decisions and processes, as opposed to decisions in the traditional domestic-international and crossing-boarders frameworks, could assume prominence, but also the adaptive complex dynamics of entrepreneurship (Etemad 2004) and international business would be synergistically linked, if not fully integrated (Dana et al. 2000). In spite of the early unease, EI is an integral part of the field now; and IE and EI are used nearly interchangeably, which point to an evolutionary and positive change over time.

\section{What is, or should be, the unit of analysis - Is it the entrepreneur, the firm, or the combination of the firm containing its founder(s), owner(s), and manger(s) and do EI decision come about?}

The older definition of IE, at the intersection of international business (IB) and entrepreneurship (E), inherited a few of the two fields' basic principles, which in turn introduced certain incompatibilities. The unit of analysis was one. The primarily focus of entrepreneurship has traditionally been the entrepreneur, founder and the managerial team, as discussed earlier. The unit of analysis in IB, however, has been the "black box" of the firm, which had been inherited from economics. In theoretical microeconomics, the context is mainly domestic and Adam Smith's famed "invisible hands" of market forces made all the decisions. However, firms in IB operate in an international context (e.g., international trade and investment are conducted across borders) and face more complex decisions (than those of a strictly domestic firm), which suggest that not only the IB's unit of analysis must be defined within multiplecountry contexts but also such firm's international decisions need to be (or are) somehow fairly and optimally made. While the nature of fairness and optimality have eluded scholarly examination so far, ${ }^{7}$ issues concerning decision-making in EI have been increasingly scrutinized.

The added complexity arising from multiple embeddedness and multi-country operations are far beyond the abilities of a firm's black box with intangible and invisible decision-makers at the helm-yet, the issue has not attracted much discussion. Naturally, IE's earlier definition (at the intersection of IB and entrepreneurship) inherited all such traditional inconsistencies, which resulted in consequent incompatibilities. The concept of EI, introduced later, where the emphasis shifted to entrepreneurial processes,

\footnotetext{
${ }^{7}$ Although the topics of fairness and optimality, or lack thereof, lie at the root of host country dissatisfaction leading to international disputes, which deserve extended discussions, they are far beyond the scope of this introductory note.
} 
abstracted from some of those difficulties to some extent, but did not resolve them entirely. Although a "visible and tangible entrepreneur" has been transplanted ${ }^{8}$ into the firm construct, the term "international" in EI is not yet well-bounded or well-defined. The international entrepreneurship of migrants and diaspora, discussed in some length in this thematic SI, exemplifies a list of yet to be resolved difficulties facing us. We further examine the term "international" from two different perspectives to stimulate further reflections, as follows:

1. From the traditional internationalization perspective. In the most basic form of internationalization - e.g., exporting, importing and licensing - products, services, and intellectual property (or proprietary information) cross boarders to enter into "foreign" markets and experience "foreignness". 9 Originally introduced by Hymer (1976), foreignness is a two-sided concept-i.e., the foreign market behavior is "foreign" to the home manager(s), and the imported products and services are initially considered as "foreign" by local consumers. Consequently, foreignness may result in less-than-optimal management, if not mismanagement, of affairs in local foreign markets on the one hand; and regardless of their inherent values, the offered products and services would not be fitting into that local market as well as their indigenous counterparts would on the other. The Process Theory of Internationalization (Johanson and Valhne 1977) proposed the four related theoretical concepts of "psychic distance," "experiential knowledge," "learning," and "commitments" that dealt with aspects of the foreignness phenomenon over time. The first one suggested entry into international markets similar to those at home (expected to have shorter psychic distance), while the next two required managers to learn about the market behavior over time and gain local market knowledge experientially in the foreign local market. The mode of entry decisions could determine the level of initial commitments (Zhou 2007), which could increase (or decrease) over time as incremental experiential knowledge was learnt. Combined, they could reduce both the mismanagement and the miss-fitting; which would in turn further enable the foreign (or international) firms to gradually learn and act similar, if not superior, to how the local firms and local managers would and consequently become more competitive using their higher local knowledge. Consider for a moment, what if the management of the internationalizing firm would be well-endowed with the pertinent foreign local experience of both the home and host markets? Would it not reduce, if not avoid, foreignness; and if so, should they not be an integral part of entrepreneurial internationalization? This clearly points not only to the importance of entrepreneurs', founders', and top management teams' international experience but also to the migrant and diaspora entrepreneurs as more-potent international entrepreneurs due to their richer international experience than those of the local managers, regardless of their country of origin.

\footnotetext{
${ }^{8}$ The term "visible and tangible entrepreneur" is a metaphor referring to the real entrepreneurial, founding, and managerial teams that make active and explicit decisions to affect the firm's growth path as opposed to markets deciding on the firm's destiny.

${ }^{9}$ In the traditional international business, goods, services, proprietary knowledge, and some resources moved internationally, but the principal entrepreneurs or managers did not-they remained at home and hence the concepts of foreign markets and foreignness.
} 
2. From the resource-based theory and competitiveness perspectives. The resourcebased view (RBV) of the firms points to the incremental value of more potent, in comparison to less potent, resources. An entrepreneur-manager with more, and possibly richer, international experience, as compared to a locally oriented with limited international experience in an internationalizing firm, are likely to reflect richer resource than otherwise. Naturally, an entrepreneur with more experiential knowledge of international markets would reduce the likelihood of mismanagement in those markets, and possibly avoid the liabilities of foreignness in such markets. Consequently, foreignness could be received positively, when it reflected higher values and newness. ${ }^{10}$

The above discussion points clearly to the case of migrant entrepreneurs that can bridge across a few inherently difficult concepts in EI due to their international movements and prior international experience. Migrant and diaspora entrepreneurs, who are richly endowed with experiential knowledge of their home markets, and possibly a few others, are therefore reflecting higher resources and well-suited to operate within, and thus be included in, IE and certainly in EI. Logically, entrepreneurially based internationalization (or EI) should prefer entrepreneurial decision-makers with richer multi-context experience, such a migrant entrepreneurs, at the helm of its internationalization than the traditional home-oriented decision-maker managers making internationalization-related decisions. They are more likely to reduce, if not avoid, the liabilities of "Foreignness" (Hymer 1976), "Newness" (Stinchcombe 1965) and "Outsidership" (Johanson and Valhne 2003 and 2009) and thus pave a smoother road for the firm to become more globally competitive at a faster rate by not suffering setbacks due to liabilities. In an evolutionary sense, the richer international experience of migrant and diaspora entrepreneurs, as discussed earlier, should qualify them as integral constituents of EI and vice versa. Following the evolutionary trajectory of EI's development so far, and in the context of this thematic SI, the experiential characteristic and international attributes of migrants and diaspora entrepreneurs may take EI to yet higher grounds. They may also challenge us to re-visit the traditional meaning of international-i.e., where only goods, services, capital and intellectual properties cross international borders, but not people - and adopt a richer multi-context and multiembeddedness concept to replace it. This new view may enable us to see farther horizons.

\section{Conclusions and implications}

We started with the question of whether or not the entrepreneur is theoretically inside the construct (or the black box) of the firm? Logically, we could have asked which entrepreneurial characteristics would provide for a better-fit into the construct of IE, and how would such entrepreneurs and firms interact with and within international market arena to enrich our views and expand our horizons? Fortunately, the guest

\footnotetext{
${ }^{10}$ Stinchcombe (1965) suggested that "newness" could also be a liability. In traditional societies, closed to change and without much exposure to barrage of new products, newness may pose a liability. However, when improved products and service offer higher values than their counterparts, they could be viewed positively without much liability, although they could replace their old counterpart gradually.
} 
editors' editorial note and the seven articles that follow raise few other complementary questions, inquisitive concepts, and discussions, which should help us to confront similar difficult questions in order to push an internationalizing firm along the evolutionary path of EI, and hopefully beyond. In the balance of this section, we pose the two following topics seemingly falling outside EI in order to encourage further scholarly discussions and to stimulate further evolutionary processes by examining issue that have alluded us so far.

i) Internationalization of locally bound goods, services, and resources. In general, internationalization results in growth and higher revenues that international markets generate, part of which are repatriated to the firm's headquarters in the firm's home market. When a firm possesses goods, service, and other resources capable of attracting revenue-generating international customers from outside to its home location (i.e., outside of where those locally bound resources are located), then nearly all of the net revenues flow into, and remain in, the home base of the firm. This is not only superior to selling those goods and services in the international markets and repatriating their net revenues but it also generates a richer experience for locals and possibly higher net revenues that all accrue and stay at home. The clear implication of this example is that IE's scope has not yet expanded wide enough to include the internationalization of locally bound resources and similar phenomena. It is, perhaps about time, that IE scholars expand their view to see the internationalization of location-bound goods and services within the EI's horizon. Etemad and Motaghi (2018) have examined cultural creative events that attract large international visitors to Canada and generate much local employment, income, and wealth, which at times surpass comparable traditional internationalizations of such events. Expectedly, their inherent complexities and challenges also exceed traditional internationalization as well.

ii) General tourism. Tourism is the generalized case of location-bound internationalization, where tourists from the far corners of the world travel to destinations that offer attractive location-bound (or location-specific) features. Such tourists spend their international funds in that location, which in turn support local employment, generate incremental income and experience as well as contributing to the tax base. They parallel, if not exceed, the benefits of exporting comparable activities. However, as discussed above, the international movements of people have not been a part of the traditional IB, nor IE, for the most parts. Although tourism has emerged as a field of its own, there is no logical reason for IE or EI scholars not to include them for their rich entrepreneurial and international challenges.

In summary, entrepreneurial internationalization has come a long way and has met many challenges already. However and as portrayed in the short discussions above, many others remain. Accordingly, the Journal of International Entrepreneurship calls upon the scholarly community to approach the above, and similar, yet-to-be-addressed topics from an EI lens and perspective. For their proven potentials in generating local employment, experience, income, and wealth, they offer promising topics for research, and deserve examination of their respective public policy issues, especially in the richly endowed emerging markets, where such attractive resources are under-utilized and the local needs are even greater than elsewhere. The journal welcome proposals for 
scholarly initiatives, papers, and even special thematic issues on such challenging frontiers, among others.

Acknowledgements This article has benefited from comments of Maria Elo and Liesl Riddle, for which I am thankful.

\section{References}

Dana LP, Etemad H, Wright R (2000) The global reach of symbiotic networks. J Euromarketing, 2000 9(2):116

Etemad H, Motaghi H (2018) Internationalization pattern of creative-cultural events: two cases from Canada. Int Bus Rev. https://doi.org/10.1016/j.ibusrev.2018.03.003(Forthcoming)

Etemad H (2005) Entrepreneurial Internationalization or international entrepreneurship, management international review, (Summer 2005), 45(3): 3-13

Etemad H (2004) International entrepreneurship as a dynamic adaptive system: towards a grounded theory, J Int Entrep, Spring 2004, $2(1$ \& 2):5-59

Friedman TL (2005) The world is flat: a brief history of the twenty-first century, Farrar, Straus and Giroux, New York, New York, 2005

Johanson J, Vahlne J-E (1977) The internationalization process of the firm: a model of knowledge development and increasing foreign market commitment. J Int Bus Stud 4:20-29

Johanson J, Vahlne J-E (1990) The mechanism of internationalization. Int Mark Rev 7:11-24

Johanson J, Vahlne J-E (2003) Business relationship learning and commitment in the internationalization process. J Int Entrep 1:83-101

Johanson J, Vahlne JE (2009) The Uppsala internationalization process model revisited: from liability of foreignness to liability of outsidership. J Int Bus Stud 40:1411-1431

Hymer SH (1976) The international operations of national firms. MIT Press, Cambridge, MA

Loustrainen, R.K. (1994), Internationalization of Finnish firms and their response to global challenge, UNU World Institute for Development Economic Research

Loustrainen (1988) Internationalization: evolution of a concept. J Gen Manag 2:34-55

Loustarinen, R. (1980) Internationalisation of the firm, Helsinki: the Helsinki School of Economics Doctoral Thesis)

Stinchcombe AL (1965) Social structure and organizations. In J. G. March (Ed.), Handbook of Organizations, 142-193, Chicago: Rand McNally

United Nations, Department of Economic and Social Affairs (2017) The International Migration Report 2017, available at https://www.un.org/development/desa/publications/

Welch L, Loustarinen R (1993) Inward-outward connections in internationalization. J Int Mark 1(1):44-56

Zhou L (2007) The effects of entrepreneurial proclivity and foreign market knowledge on early internationalization. J World Bus 42(3):281-293 